\title{
A CONSTITUCIONALIZAÇÃO DA CIÊNCIA, TECNOLOGIA E INOVAÇÃO COMO INSTRUMENTO DE EFETIVAÇÃO DO DIREITO A INOVAÇÃO. ${ }^{1}$
}

\author{
Gilberto Batista Santos ${ }^{2}$ \\ Edmario Nascimento da Silva ${ }^{3}$
}

\section{RESUMO}

O presente artigo tem por objetivo realizar um estudo acerca da Constitucionalização do direito a Ciência, Tecnologia e Inovação. Visto que desde a promulgação da Constituição Federal de 1988, existe uma relação proximal que liga o avanço tecnológico ao direito social posto em nossa Constituição Federal no Capítulo IV, artigos 218 e 219 (capítulo especifico para a Ciência, Tecnologia e Inovação). Para tanto, aplica-se à pesquisa o método dedutivo e o método de Abordagem Baseada em Direitos (Right-Based Aprooach - RBA), método vinculado ao Grupo de Pesquisa Gestão, Educação e Direitos Humanos (GEDH na Universidade do Estado da Bahia (UNEB).

Palavras-chave: Acesso; Constitucionalização da Ciência; Tecnologia e Inovação; Direito a Inovação; Abordagem Baseada em Direitos.

\section{THE CONSTITUTIONALIZATION OF SCIENCE, TECHNOLOGY AND INNOVATION AS AN INSTRUMENT OF EFFECTIVENESS OF THE RIGHT TO INNOVATION.}

\begin{abstract}
The purpose of this article is to study the Constitutionalisation of the right to Science, Technology and Innovation. Since, since the enactment of the Federal Constitution of 1988, there has been a proximate relationship that links the technological advance to social law, as set forth in our Federal Constitution in Chapter IV, articles 218 and 219 (specific chapter for Science, Technology and Innovation). To that end, the Deductive Method and the RightBased Approach (RBA) method, a method linked to the Research Group on Management, Education and Human Rights (GEDH at the State University of Bahia (UNEB ).
\end{abstract}

Keywords: Access; Constitutionalisation of Science; Technology and Innovation; Right to Innovation; Rights Based Approach.

\section{INTRODUÇÃO}

\footnotetext{
${ }^{1}$ Esse artigo é um resumo da Dissertação de Mestrado deste autor, apresentado em agosto de 2017, vinculado ao GESTEC Gestão e Tecnologia Aplicada à Educação - UNEB, associada a linha de pesquisa de Inovação e Direitos Humanos.

2 Professor universitário, Advogado, especialista em Direito Público e Constitucional, Pesquisador no Observatório de Direitos Humanos e Mestre em Gestão e Tecnologia Aplicada à Educação - UNEB. E-mail: advgilbertobatista@gmail.com

${ }^{3}$ Professor universitário, Advogado, especialista em poliitica e estratégia, Coordenador do grupo de estudos de Direito e Pós Modernidade da Unirb-Alagoinhas, Mestre em Crítica Cultural - UNEB. E-mail: edmarioadv@gmail.com
} 
No século XXI, a sociedade é partícipe e testemunha de momentos e movimentos cruciais na história da humanidade, hoje sabemos mais sobre o funcionamento da natureza do que há cem anos e podemos esperar saber ainda mais daqui a um século. É fácil compreender e aceitar o conceito de progresso e ser otimista no que diz respeito à sua extensão no futuro próximo.

Nesse sentido, a utilização crescente de expressões como "Era da Informação", "Sociedade da Informação", "Nova Economia", entre outras, anunciam as mudanças em curso de uma economia voltada para o "mundo tecnológico", onde o tempo, as distâncias, as barreiras físicas são literalmente suprimidas.

Em consonância com esse desafio de se estabelecer no país uma cultura de inovação, o Brasil vem instituindo diversas leis que versam sobre o tema. As chamadas "Leis da Inovação", refletem a necessidade em contar com dispositivos legais eficientes que dispõe sobre incentivos à inovação, à pesquisa científica e tecnológica. Nesse sentido, podemos afirmar que o direito é reflexivo, ele é resultante de um momento social, por conta desse cenário é que os Estados devem buscar instrumentos que possam viabilizar o ajuste do sistema jurídico em relação à CTI.

Nesse interim, as repercussões jurídicas acerca das Inovações Tecnológicas, bem como o reconhecimento da Inovação como um direito, tem sido objeto de amplas discussões envolvendo os profissionais da área do Direito. O fato é que a inovação tecnológica mudou a sociedade e continua a desafiar mudanças cirando novos paradigma na vida social. Neste contexto, a inovação tecnológica desafia também a criação de Políticas Públicas para impulsionar e proteger os bens intangíveis, incorpóreos e instantâneos, propagados pela inovação.

A realização dessa pesquisa justifica-se então, pela necessidade de reflexão da Sociedade sobre o paradigma contemporâneo da CTI a partir da promulgação da Constituição Federal de 1988, principalmente pela relação proximal que liga o avanço tecnológico ao direito social. Haja visto estar posto em nossa Constituição Federal um capítulo especifico para a Ciência, Tecnologia e Inovação (Capítulo IV, artigos 218 e 219).

Para tanto o objetivo geral tem como propósito, analisar o processo de Constitucionalização da Ciência, Tecnologia e Inovação - CTI. A elucidação do tema é de suma importância para o equilíbrio na relação jurídica.

A pesquisa trará caráter qualitativo, vez que, buscamos analisar as Normas que formam a Constitucionalização da Ciência, Tecnologia e Inovação no Brasil. É importante frisar que, a realização de uma pesquisa dessa natureza obedece a um ritmo bastante dinâmico, em um processo de levantamento e análise de bibliografia especializada e a coleta e análise de Leis, (Pesquisa Documental), também recorremos aos acervos do Conselho Nacional de Desenvolvimento Científico e Tecnológico (CNPq), do MCTI, Senado, Câmara dos Deputados. 


\section{A CONSTITUCIONALIZAÇÃO DA CIÊNCIA, TECNOLOGIA E INOVAÇÃO COMO INSTRUMENTO DE EFETIVAÇÃO DO DIREITO A INOVAÇÃO}

Como recorte da pesquisa abordaremos a Carta Magna de 1988 para demonstrar o processo de Constitucionalização da CTI, já que a Constituição Federal de 1988 (Constituição Cidadã), representa um grande avanço no tocante à Ciência, Tecnologia e Inovação, quando trouxe em sua redação a responsabilidade do Estado na promoção da CTI.

Deste modo, para melhor entendermos o contorno e a extensão da Invocação Tecnológica na atual Constituição, traçaremos uma análise das variações sofridas por este direito dado por cada uma das Constituições que o Brasil já possuiu ao longo dos tempos. A análise compreenderá desde a Constituição de 1824 até a Constituição de 1988.

É imprescindível a discussão acerca do mencionado tema, visto que é evidente a importância jurídica, política e econômica da matéria, não podendo ser debatido o tema relativo sem considerar que se trata de um complexo processo que vem se desenrolando ao longo do tempo.

\section{A CONSTITUCIONALIZAÇÃO DA CIÊNCIA, TECNOLOGIA E INOVAÇÃO}

Para melhor entendermos o contorno e a extensão da Invocação Tecnológica na atual Constituição, oportuno se faz preliminarmente traçar uma análise razoável da proteção que fora conferida a este direito nas Constituições pátrias que lhe são anteriores, vez que trata-se de um direito que já gozava de previsibilidade ainda que de maneira diferenciada.

Ao analisar especificadamente a normatização do tema em cada uma das Cartas Constitucionais que o Brasil já teve, podemos verificar caracteres próprios de cada fase temporal refletidos na disposição dos direitos ora expostos, decorrentes invariavelmente das ideologias, valores, influências políticas, jurídicas e sociais (externas e internas) reinantes nos períodos em que foram outorgadas ou promulgadas.

A primeira Constituição do Brasil possui peculiaridades e características que a diferenciam bastante das que se seguiram, não somente por ter sido a primeira carta jurídica do Estado, mas por curiosidades naquilo que a constituiu e no modo como tratou determinados direitos.

Vale ressalvar que Dom Pedro I, mostrando declarado descontentamento com a produção do que estava sendo elaborado pela Assembleia Constituinte para redigir a primeira Constituição, determinou a sua dissolução, pois não lhe agradava a ideia de ter seu poder de império limitado. 
Assim, o sucessor de D. João, desfazendo a Constituinte, convocou alguns ministros de sua confiança e incumbi-lhes de redigir a Constituição, tendo também participado de sua feitura, para assim garantir que fosse mantido o seu poder, chamado de Poder Moderador.

Segundo Bastos (1999):

A Constituição outorgada de 1824 era marcada sem dúvida, por um grande liberalismo que se retratava, sobretudo, no rol dos direitos individuais que era o que havia de mais moderno na época, como também na adoção da separação de poderes que, além dos três clássicos, acrescentava um quarto: o Poder Moderador. (BASTOS, 1999).

Juridicamente falando, esta Constituição teve forte influência do constitucionalismo inglês, embora tenha sido omissa em tratar diretamente do tema de CTI, por apenas disciplinar este em relação a educação, estabelecendo a gratuidade da instrução primária e incluir a criação de colégios e universidades, considerando como a base dos direitos civis e políticos dos cidadãos. Vejamos a disposição do artigo 179, caput e inciso XXXIII:

Art. 179 - A inviolabilidade dos Direitos Civis, e Politicos dos Cidadãos Brazileiros, que tem por base a liberdade, a segurança individual, e a propriedade, é garantida pela Constituição do Império, pela maneira seguinte: [...]

XXXIII. Collegios, e Universidades, aonde serão ensinados os elementos das Sciencias, Bellas Letras, e Artes. (BRASIL, 1824.).

Vemos que a CTI era assegurada, com a consequente dos direitos inerentes a matéria educacional foi registrada em dois incisos do artigo 179, que trata da inviolabilidade dos direitos civis e políticos dos cidadãos brasileiros, em que determina "a instrução pública é gratuita a todos os cidadãos", em "Colégios e Universidades, onde seriam ensinados os elementos das Ciências, Belas Artes e Letras".

A segunda Constituição brasileira foi a primeira Carta Política republicana, proclamada em 24 de fevereiro de 1891 e teve como meta estabelecer os princípios republicanos e adotar o sistema de governo presidencialista. Tinha traços do estado liberal.

Assim como a Constituição antecedente, a Carta de 1891 foi omissa no que tange à matéria de CTI. Entretanto, torna-se imperioso destacar que alguns dos institutos de pesquisa que tiveram relevante importância histórica na atividade científica do país foram criados nesse período. Segundo Silva (2008) apud Schwartzman (1979), no final do século XIX, foram criados o Instituto Agronômico de Campinas (1887), o Instituto Vacinogênico de São Paulo (1892), o Bacteriológico de São Paulo (1893) e o Butantã (1899) e o de Manguinhos (1900). 


\section{A CONSTITUCIONALIZAÇÃO DA CIÊNCIA, TECNOLOGIA E INOVAÇÃO COMO INSTRUMENTO DE EFETIVAÇÃO DO DIREITO A INOVAÇÃO}

Na Carta de 1891, a CTI foi enumerada como Educação entre as atribuições do Congresso Nacional, no Artigo 34, inciso 30, que determina a competência privativa de "legislar sobre a organização municipal do Distrito Federal, bem como sobre a policia, o ensino superior e os demais serviços que na Capital forem reservados para o governo da União" (BRASIL, 1981).

Percebe-se que a disposição desse direito possuía um aspecto eminentemente ligado educação, seguindo a tradição do Império, enfatiza-se, mais uma vez, a nível nacional, o ensino superior. A novidade em relação a Constituição de 1824, foi que a Educação não foi considerada matéria de competência exclusiva ou privativa da União, estava registrada no elenco de matérias enumeradas como elemento orgânico e matéria do Poder Legislativo.

Em 16 de julho de 1934 foi promulgada a terceira constituição do país e segunda carta política republicana. Esta Constituição nasceu sob influência das correntes de pensamento predominantes do fim da Primeira Guerra Mundial. A influência das Constituições de Weimar (1919) e da Espanhola (1931) são notórias.

Outro importante fator histórico foi a crise econômica de 1929, bem como o nascimento de diversos movimentos sociais que diligenciavam melhores condições de vida, trabalho e distribuição de renda, o que gerava importantes debates quanto à legitimidade da democracia liberal e do liberalismo econômico.

Em seu artigo 113, parágrafo $9^{\circ}$ dispunha sobre a liberdade de manifestação do pensar:

\footnotetext{
Art. 113 - A Constituição assegura a brasileiros e a estrangeiros residentes no País a inviolabilidade dos direitos concernentes à liberdade, à subsistência, à segurança individual e à propriedade, nos termos seguintes: [...]

$9^{\circ}$ - Em qualquer assunto é livre a manifestação do pensamento, sem dependência de censura, salvo quanto a espetáculos e diversões públicas, respondendo cada um pelos abusos que cometer, nos casos e pela forma que a lei determinar. Não é permitido anonimato. É segurado o direito de resposta. A publicação de livros e periódicos independe de licença do Poder Público. Não será, porém, tolerada propaganda, de guerra ou de processos violentos, para subverter a ordem política ou social. (BRASIL, 1934).
}

De modo semelhante as Constituições anteriores, a Carta de 1934, apenas reserva o a CTI um espaço reservado em outras matérias, no caso especifico no Capítulo II, do Título V (Da Família, Da Educação e Da Cultura), mais especificamente no Artigo 148, onde estabelecia que no campo educacional, à União, os Estados e aos Municípios cabe a tarefa de: "favorecer e animar o desenvolvimento das ciências, das artes e da cultura em geral, proteger 
os objetos de interesse histórico e o patrimônio artístico do país, bem como prestar assistência ao trabalhador intelectual" (BRASIL, 1934).

A Carta política de 1934 estabelece a competência concorrente entre à União e os Estados no papel de "difundir a instrução pública em todos os graus" (BRASIL, 1934). Podendo os Estados que descumprissem o preceito constitucional suportar uma intervenção federal, conforme estabelecido no artigo12, parágrafo primeiro do referido diploma.

Outra importante novidade, é a previsão expressa no texto de Constitucional, estabelecendo que os Estados não podem aplicar menos de vinte por cento da renda resultante dos seus impostos, no custeamento e no desenvolvimento dos sistemas educativos, enquanto a União e os Municípios devem aplicar pelo o percentual mínimo de dez por cento, conforme estabelecido no artigo 156. O texto Constitucional, determina ainda que os Estados deveriam reservar parte dos patrimônios territoriais para que fossem formados fundos de educação, devendo proceder da mesma maneira a União e o Distrito Federal.

A Constituição de 1937 foi a quarta carta política a viger no Brasil. A diferença temporal que a separa da anterior é muito curta, levando em conta a vigência da Constituição de 1934 que foi de apenas três anos, tendo sido "engolida" por esta que lhe sucedeu.

Esta Constituição foi elaborada sob influência direta da Constituição Polonesa (conhecida como "Polaca") e com ela guardava muitas semelhanças e possuía caracteres do regime fascista. Não foi promulgada, mas outorgada através de um golpe de Estado promovido por Getúlio Vargas, que se aproveitou do momento de intensa crise políticoideológica que se radicalizava no país.

A Constituição de 1937, conferia amplos poderes ao Executivo, demonstrando seu caráter antidemocrático, que se evidenciava quando da imposição de limitações ao direito da liberdade de expressão. Entretanto, do ponto de vista da CTI, foi a primeira a abordar o tema, reservando o Artigo 128 para estabelecer que:

\footnotetext{
A arte, a ciência e o seu ensino são livres a iniciativa individual e a associação ou pessoas coletivas, públicas e particulares. É dever do Estado contribuir, direta ou indiretamente, para o estímulo e desenvolvimento de umas e de outro, favorecendo ou fundando instituições artísticas, científicas e de ensino". (BRASIL, 1937).
}

Como se pode observar, a Carta "polaca" foi a primeira a constitucionalizar a Ciência, explicitando a obrigação Estatal com o desenvolvimento científico, porém, ainda constando diversas restrições, orientando os limites legais dispostos em seu próprio texto. Nesse 


\section{A CONSTITUCIONALIZAÇÃO DA CIÊNCIA, TECNOLOGIA E INOVAÇÃO COMO INSTRUMENTO DE EFETIVAÇÃO DO DIREITO A INOVAÇÃO}

diapasão, segundo Bastos (1999), o Artigo 128 não fez referência alguma a formação de recursos humanos, não tratando, quanto aos meios e condições do Estado contribuir com o estímulo e desenvolvimento estabelecimento de ensino e instituições científicas.

Neste período também foi criado o Departamento de Imprensa e Propaganda (DIP), que possuía dentre outros objetivos, difundir a ideologia do Estado Novo em todos os lugares do território nacional.

A quinta Constituição pátria, foi promulgada em 18 de setembro de 1946, como decorrência da convocação de uma Constituinte pelo presidente Eurico Gaspar Dutra, que venceu a eleição convocada por Getúlio Vargas. Nela, percebemos referências das Constituições Republicanas de 1891 e 1934.

Antes de adentramos na relação da Constituição com a Ciência, Tecnologia e Inovação, é interessante trazer uma observação sobre a importância que possui essa Carta Política. De acordo com o jurista Celso Ribeiro Bastos:

\footnotetext{
A Constituição de 1946 se insere entre as melhores, senão a melhor, de todas que tivemos. Tecnicamente é muito correta e do ponto de vista ideológico traçava nitidamente uma linha de pensamento libertária no campo político sem descurar da abertura para o campo social que foi recuperada da Constituição de 1934. (BASTOS, 1999.).
}

Essa visão certamente foi favorecida pela complexidade histórica que envolveu a carta anterior e por conta da Carta de 1946, ter ocasionado uma proteção maior aos direitos individuais. Ainda segundo Bastos (1999), a Constituição de 1946 é uma Constituição Republicana, Federativa e Democrática.

Passemos agora a análise do que a carta de 1946 trouxe em relação a Ciência, Tecnologia e Inovação. No que pese todos os elogios do jurista Celso Ribeiro Bastos, no campo da CTI, a Carta apresentou uma redação reduzida em relação sua antecessora de 1937, versando em seu artigo 173 que: "as ciências, as letras e as artes são livres" (BRASIL, 1946).

De acordo com Silva (2008), a Constituição de 1946 deixou uma grande lacuna em relação as obrigações do Estado em promover o progresso científico, o que segundo a autora é de causar uma grande surpresa, tendo em vista que o ano de 1946 representou o primeiro ano após a segunda Grande Guerra que foi um período de ampla produção científica e tecnológica no mundo.

Para Silva (2008) apud De Paula (2004), o fato do Brasil estar subordinado a política econômica imposta pelos Estados Unidos e foi um dos fatores impeditivos de apresentar 
avanços científicos e tecnológicos, principalmente, quanto a tecnologia bélica e, consequentemente, ao crescimento da informática em que avançaram os demais Estados envolvidos.

É importante destacar, que a Carta de 1946 não apresentou nenhuma forma de estimular a formação de recursos humanos, e tampouco fornece os meios de trabalho. Segundo Silva (2008) ao enunciar no artigo 173 que as ciências, as letras e as artes são livres, sendo livres se desvinculam da atividade estatal e, consequentemente, de seu auxílio. Resta claro que as ciências, letras e artes, exercidas desta forma poderia ser vista como uma maneira de estimular a dedicação à livre iniciativa, voltando a ser sem a submissão a critérios previamente definidos do Estado.

Uma novidade trazida nesta Constituição se refere ao capítulo reservado à Educação e à Cultura, o que envolve os Artigos 166 a 175, perfazendo a alteração do percentual de recursos destinados, pelos Estados e municípios nos seus sistemas de ensino. Os Estados, os Municípios e do Distrito Federal, deveriam aplicar pelo menos vinte por cento da renda resultante dos impostos na manutenção e desenvolvimento do ensino, enquanto os dez por cento ficam a cargo da União. Curiosa esta disposição, ampliando a participação dos Estados, na política educacional, refletindo o regime representativo.

A sexta constituição brasileira, outorgada em 24 de janeiro de 1967, pelo Regime Civil/Militar. Antes de passarmos ao que interessa, mister se faz compreender o seu contexto histórico, que "justificava" o seu texto legal e tudo o que seria ocasionado a partir deste período.

A história recente do Brasil é marcada por traumas causados durante o período da ditadura militar (1964-1985), com a violação de direitos e a imposição de torturas e degradação de pessoas contrárias ao regime, vilipendiando a existência, a dignidade e o respeito de diversos cidadãos que buscavam expressar suas ideias e oposição ao regime de exceção. A suspensão dos direitos civis e políticos implicou em atraso para a democracia e para a organização da sociedade civil.

O Regime Militar oficialmente tem início no Brasil com a assunção dos militares ao poder, no dia $1^{\text {o }}$ de abril de 1964. A agenda política deste regime incluía, além da supressão e restrição de direitos constitucionais, principalmente das liberdades individuais, também perseguição política, prisão e tortura dos seus opositores. 
Com o golpe de 1964 e a assunção dos militares ao poder, entendeu-se que a Constituição de 1946 não atendia àquele projeto de governo e nem favorecia às necessidades e interesses daquela classe. Isso se confirmava à medida que iam sendo editadas sucessivas emendas. Outro ato que confirmava o desinteresse naquela Constituição era a edição de atos institucionais que praticamente a anularam, fazendo-os outorgarem uma nova Constituição.

Após todas essas considerações, passaremos a analisar o tratamento dado a Ciência, Tecnologia e Inovação nesta Constituição. A CTI, consta no título IV (Da Família, da Educação e da Cultura), o Artigo 171, estabelece que: “As ciências, as letras e as artes são livres”, sendo introduzido no parágrafo único do Artigo 171 uma das maiores inovações até o presente momento, dispõe que: “o Poder Público incentivará a pesquisa e o ensino científico e tecnológico".

Segundo Silva (2008), a Carta Política de 1967, trouxe termos novos que não se encontravam na redação das Constituições anteriores, como a presença dos termos pesquisa e tecnologia que não se encontram na redação de suas Cartas precursoras.

Pontes de Miranda (1987) aponta que havia em alguns setores do movimento de 1964, o reconhecimento de que faltava ao Brasil o conhecimento científico e tecnológico. Mas apenas se deu uma redação mais restrita programática em termos gerais, sem percentual de verbas e sem criação de direitos aos que se dedicavam à ciência e à tecnologia.

Quanto a formação de recursos humanos e seu provimento profissional, a redação da Carta de 1967 é ausente, porém fica implícito na própria redação do parágrafo pelo legislador, que o incentivo estatal ao desenvolvimento científico e tecnológico só pode ser alcançado mediante a formação profissional de pessoal especializado.

No que tange a Educação, a matéria foi colocada como sendo exclusiva da União. Conforme podemos observar no disposto no Artigo $8^{\circ}$, XVII: "Compete à União legislar sobre diretrizes e bases da educação nacional e normas gerais sobre desportos". É importante destacar que, conforme estabelecido no inciso XV do mesmo Artigo $8^{\circ}$, a Competência da União não excluiu a dos estados para legislar supletivamente sobre as matérias referentes as diretrizes e bases da educação.

Nesse sentido, a Constituição de 1967 garantiu que os Estados pudessem se organizar pelas constituições e leis que adotassem. Entretanto, ressalvava que, para receber auxílio da União aos Estados, estes deveriam entregar, previamente, um plano de sua aplicação, 
conforme estabelecido no Artigo 13, §5 . Neste caso, Silva (2008), aponta que os estados deveriam justificar, com projetos de investimento, a solicitação de auxílio financeiro à União.

Quanto aos recursos destinados ao setor educacional, a Carta de 1967 reafirmou a obrigação compulsória já estabelecida nas Constituições anteriores dos Estados não poderem aplicar menos do que vinte e cinco por cento, de suas receitas resultantes de impostos, conforme previsto no Artigo 176, $\S 4^{\circ}$.

Em 17 de outubro de 1969 foi publicada a Emenda Constitucional (EC) ${ }^{4} \mathrm{n}^{\text {o }}$ 01, que modificou de forma abrupta e ampla em diversos aspectos o teor da Constituição de 1967. No diapasão da necessidade de estimular o desenvolvimento tecnológico a Emenda Constitucional de 1969, estabeleceu em seu Artigo 179, parágrafo único, uma redação similar ao Artigo 171, parágrafo único da Constituição de 1967, estabelecendo da mesma maneira as responsabilidades do Estado em proporcionar o desenvolvimento científico, com apenas uma modificação no parágrafo único do Artigo 179: “(...)Parágrafo único. O Poder Público incentivará a pesquisa e o ensino científico e tecnológico.”. O destaque ao ensino científico e tecnológico mostra o entendimento do legislador a respeito da importância da educação no patrocínio da produção científica.

Da mesma forma que a Constituição de 1967, a Emenda Constitucional de 1969 também não versou sobre a formação de recursos humanos e seu emprego profissional. No entanto, cabe apontar que a Emenda 1969 acarretou algumas modificações, quanto ao exercício da liberdade das ciências, letras e artes, introduzindo as ressalvas que estavam dispostas $\S 8^{\circ}$ do Artigo 153.

Em regra, estava permitida pelo texto legal a manifestação da exteriorização do pensamento, com menção expressa no que diz respeito inclusive ao seu conteúdo, citando-se aquelas que contivessem teor político ou filosófico. A proibição da censura se fazia presente, com exceção quanto aos atos de entretenimento, bem como a já conhecida responsabilidade pelos abusos cometidos e outras disposições presentes em cartas anteriores.

A novidade aqui é a previsão de qualquer exteriorização (inclusive cientifica) que pudesse afrontar ou contrariar a moral e os bons costumes, termos que ainda hoje geram controvérsias e propiciam debates na órbita jurídica.

\footnotetext{
${ }^{4}$ Entre os juristas arrasta-se até os dias de hoje discussões acerca de se poder considerar esta emenda como uma nova constituição, visto ter ela suprimido praticamente todo o texto da Carta Política anterior, enquanto outros discordam, encarando-a mesmo como mera emenda constitucional, que apesar de forma legal, carecia de legitimidade em face do contexto em que ela surgiu e de seu conteúdo material.
} 
Neste espaço, oportuna é a lição de Zisman (2003, p. 65):

Com os termos genéricos e vagos moral e bons costumes, que ensejavam a limitação da manifestação do pensamento, o poder estatal à época restringiu abusivamente as liberdades de que trata o dispositivo, prejudicando e quase que suprimindo a liberdade de expressão. Houve ainda, diversas normas regulamentadoras da censura às exibições cinematográficas, que sob o aspecto político, atingiam o filme por inteiro, que não poderia ser exibido, pois poderia acarretar perturbações diplomáticas, ou na ordem interna. (ZISMAN, 2003, p. 65).

Embora, seja de bom alvitre relembrar que o momento histórico brasileiro era da ditadura militar, quando as liberdades de criação de certos atos que atentassem contra os interesses de ordem impostas pelo Estado, Pontes de Miranda (1987, p.365) abaliza que a ciência esta sempre em contínua renovação e quem tivesse de ensinar a ciência dos livros didáticos, ou, até, dos grandes livros naquele momento enfrentaria serias dificuldades, pois o texto legal não acompanhava evolução da cultura e da ciência que eram, naturalmente, censurados.

Com a finalidade de melhor esclarecer os principais dispositivos constitucionais em relação e CTI, apresentaremos agora uma tabela com os dispositivos das respectivas Constituições:

\begin{tabular}{|c|c|}
\hline CARTA MAGNA & ABORDAGEM CONSTITUCIONAL EM CTI \\
\hline 1824 & Omissa \\
\hline 1891 & Omissa \\
\hline 1934 & Omissa \\
\hline 1937 & $\begin{array}{l}\text { Art. } 128 \text { - A arte, a ciência e o seu ensino são livres à iniciativa individual e à de } \\
\text { associações ou pessoas coletivas, públicas e particulares. É dever do Estado contribuir, } \\
\text { direta e indiretamente, para o estímulo e desenvolvimento de umas e de outro, } \\
\text { favorecendo ou fundando instituições artísticas, científicas e de ensino. }\end{array}$ \\
\hline 1946 & $\begin{array}{l}\text { Art. 173. As ciências, as letras e as artes são livres. } \\
\text { Art. 174. O amparo à cultura é dever do Estado. } \\
\text { Parágrafo Único: A lei promoverá a criação de institutos de pesquisa, de preferência } \\
\text { junto aos estabelecimentos de ensino superior. }\end{array}$ \\
\hline 1967 & $\begin{array}{l}\text { Art. } 171 \text { - As ciências, as letras e as artes são livres. } \\
\text { Paragrafo único: O poder publico incentivará a pesquisa cientifica e tecnológica. }\end{array}$ \\
\hline 1969 & $\begin{array}{l}\text { Art. 179. As ciências, as letras e as artes são livres ressalvados o disposto no parágrafo } \\
8^{\circ} \text { do art. } 153 \text {. Parágrafo único: O poder público incentivará a pesquisa e o ensino } \\
\text { científico e tecnológico. }\end{array}$ \\
\hline
\end{tabular}

Quadro Comparativo dos Dispositivos Constitucionais.

Fonte: Elaboração do autor. 
É nítido o papel que o Estado deve ter na promoção e incentivo da ciência e tecnologia, bem como, seu importante papel na construção das politicas publicas de ciência e tecnologia, como solução de problemas nacionais e ao avanço do sistema produtivo nacional.

Segundo Silva (2008) apud Gonçalves e Junqueira (2004) esses dispositivos, mais do que legislações especificas decorrentes de uma norma constitucional explicita, sustentam a estruturação de regimes diferenciados para a ciência e tecnologia nos Estados.

\section{A CIÊNCIA, TECNOLOGIA E INOVAÇÃO NA CONSTITUIÇÃO DE 1988}

A Constituição da República Federativa do Brasil, promulgada em 05 de outubro de 1988, sob a ótica do contexto mundial, nasceu no momento da consolidação do fenômeno da Globalização. Este por sua vez, nasceu impulsionado pela Revolução das Comunicações, que foi um acontecimento da história que permitiu que fossem diluídas as fronteiras entre os Estados, havendo a possibilidade de se acessar informações em uma escala antes tida como impensada e num tempo recorde.

Nos atendo detidamente naquilo que interessa a esta pesquisa, esta Constituição integrada a uma necessidade mundial, buscou o progresso do desenvolvimento científico, da pesquisa e da capacitação tecnológicas, erigindo ao Estado o dever de incentivá-las e promovê-las. Para a efetivação de parte destes objetivos, os artigos 218 e 219 apresentam as diretrizes de um verdadeiro programa tecnológico na Constituição brasileira.

$\mathrm{Na}$ vigente Constituição a CTI pela primeira vez na história do Direito Constitucional Brasileiro, consta em um capitulo especial dedicado a ordem social, no Capítulo IV do Titulo VIII. A Carta Constitucional deu uma nova perspectiva a matéria, buscando ampliar a sua regulamentação, apresentando em um capítulo separado e próprio, diferentemente do encontrado nas Constituições anteriores, que tratava a matéria como ciência, letras e artes.

Conforme Silva (2008), apesar do desenvolvimento da CTI, não ser inteiramente subordinado a Carta Magna, uma vez que deve ser alcançado principalmente por meio de um amadurecimento cultural, a autora aponta que é evidente a importância jurídica, política e, sobretudo econômica da matéria. Assim, a pesquisa tecnológica, nos termos da Constituição de 1988, deve destinar-se, preponderantemente, para a solução dos problemas brasileiros e para o desenvolvimento do sistema produtivo nacional e regional. 


\section{A CONSTITUCIONALIZAÇÃO DA CIÊNCIA, TECNOLOGIA E INOVAÇÃO COMO INSTRUMENTO DE EFETIVAÇÃO DO DIREITO A INOVAÇÃO}

Silva (2008) apud Cretella Júnior (1993) apontam que o legislador constituinte consagrou inúmeros dispositivos na Carta Política vigente a ciência e a tecnologia. A Inovação recebeu tratamento peculiar, propiciar os meios de acesso à ciência.

No que pese a maior preocupação dada pela vigente Carta Política, foi a Emenda Constitucional 85/2015 que atribuiu ao Estado, a promoção do desenvolvimento científico, da pesquisa, da capacitação científica e tecnológica e da inovação. Para melhor esclarecimento das alterações perpetradas pela EC 85/2015, apresentaremos um quadro comparativo das principais alterações.

A primeira alteração que apresentaremos é referente a competência comum atribuída a todos os entes (União, Estado e Município), para legislar sobre a matéria de CTI, atribuída pela EC 85, desde que respeitadas as regras gerais impostas pela União.

\begin{tabular}{|c|c|}
\hline Antes & Atualmente \\
\hline $\begin{array}{l}\text { Art. 23. É competência comum da União, dos } \\
\text { Estados, do Distrito Federal e dos Municípios: }\end{array}$ & $\begin{array}{l}\text { Art. 23. É competência comum da União, dos Estados, do } \\
\text { Distrito Federal e dos Municípios: }\end{array}$ \\
\hline $\begin{array}{l}\mathrm{V} \text { - proporcionar os meios de acesso à cultura, à } \\
\text { educação e à ciência; }\end{array}$ & $\begin{array}{l}\text { V - proporcionar os meios de acesso à cultura, à educação, à } \\
\text { ciência, à tecnologia, à pesquisa e à inovação; (Redação } \\
\text { dada pela Emenda Constitucional n }{ }^{\circ} 85 \text {, de 2015) }\end{array}$ \\
\hline \multicolumn{2}{|l|}{ Fonte: Elaboração do autor. } \\
\hline \multicolumn{2}{|c|}{ Da leitura do artigo, fica claro que a referida emenda estabeleceu que compete a todos } \\
\hline
\end{tabular}

\begin{tabular}{|c|c|}
\hline Antes & Atualmente \\
\hline $\begin{array}{l}\text { Art. 24. Compete à União, aos Estados e ao } \\
\text { Distrito Federal legislar concorrentemente sobre: }\end{array}$ & $\begin{array}{l}\text { Art. 24. Compete à União, aos Estados e ao Distrito Federal } \\
\text { legislar concorrentemente sobre: }\end{array}$ \\
\hline IX - educação, cultura, ensino & $\begin{array}{l}\text { IX - educação, cultura, ensino, desporto, ciência, tecnologia, } \\
\text { pesquisa, desenvolvimento e inovação; (Redação dada pela } \\
\text { Emenda Constitucional n }{ }^{\circ} 85 \text {, de 2015) }\end{array}$ \\
\hline
\end{tabular}

Fonte: Elaboração do autor.

Nessa baila, para tentar aumentar o desenvolvimento tecnológico e de inovação, a EC 85 permitiu à União, aos Estados, ao Distrito Federal e aos Municípios que pudessem firmar instrumentos de cooperação com órgãos, entidades públicas e com entidades privadas, podendo inclusive compartilhar recursos humanos especializados.

É importante frisar, que a Emenda Constitucional, também possibilitou a transposição, remanejamento, ou transferências de recursos de uma categoria de programação, no âmbito das atividades de ciência, tecnologia e inovação, mediante ato do Poder Executivo, sem a necessidade de prévia autorização legislativa. 
Explicando a definição e a diferença de cada um desses instrumentos, Tigre (2006) ensina que os remanejamentos podem ser entendidos como realocações na organização de um ente público com destinação de recursos de um órgão para outro.

As Transposições são realocações no âmbito dos programas de trabalho dentro do mesmo órgão. Já as Transferências são realocações de recursos entre as categorias econômicas de despesas, dentro do mesmo órgão e do mesmo programa de trabalho, ou seja, repriorizações dos gastos a serem efetuados.

Com efeito, verifica-se que o art. 167, VI, da CRFB, institui vedação "a transposição, o remanejamento ou a transferência de recursos de uma categoria de programação para outra ou de um órgão para outro, sem prévia autorização legislativa”.

No entanto, o $\S 5^{\circ}$, adicionado pela Emenda Constitucional 85 de 2015, apresenta uma extraordinário novidade:

\begin{tabular}{|c|c|}
\hline Antes & Atualmente \\
\hline Art. 167. São vedados: & Art. 167. São vedados: \\
\hline $\begin{array}{l}\text { VI - a transposição, o remanejamento ou a } \\
\text { transferência de recursos de uma categoria de } \\
\text { programação para outra ou de um órgão para outro, } \\
\text { sem prévia autorizacão legislativa; }\end{array}$ & $\begin{array}{l}\text { VI - a transposição, o remanejamento ou a transferência de } \\
\text { recursos de uma categoria de programação para outra ou de } \\
\text { um órgão para outro, sem prévia autorização legislativa; }\end{array}$ \\
\hline Não havia $\S 5^{\circ}$ & $\begin{array}{l}\S 5^{\circ} \text { A transposição, o remanejamento ou a transferência de } \\
\text { recursos de uma categoria de programação para outra } \\
\text { poderão ser admitidos, no âmbito das atividades de ciência, } \\
\text { tecnologia e inovação, com o objetivo de viabilizar os } \\
\text { resultados de projetos restritos a essas funções, mediante ato } \\
\text { do Poder Executivo, sem necessidade da prévia autorização } \\
\text { legislativa prevista no inciso VI deste artigo. (Incluído pela } \\
\text { Emenda Constitucional } n^{\circ} 85 \text {, de } 2015 \text { ) }\end{array}$ \\
\hline
\end{tabular}

Fonte: Elaboração do autor.

Cabe ressaltar que embora seja permitindo ao administrador efetivar mudanças, realinhando, nos limites legais permitidos, as prioridades a serem atendidas, estas devem estar adequadamente motivadas para que não sirvam de uma disfarçada exibilização qualitativa do orçamento.

A Emenda Constitucional, também inseriu nas atribuições do Sistema Único de Saúde SUS o de incrementar a inovação em suas áreas de atuação.

\begin{tabular}{|c|c|}
\hline Antes & Atualmente \\
\hline $\begin{array}{l}\text { Art. 200. Ao sistema único de saúde compete, além } \\
\text { de outras atribuições, nos termos da lei: }\end{array}$ & $\begin{array}{l}\text { Art. } 200 \text {. Ao sistema único de saúde compete, além de outras } \\
\text { atribuições, nos termos da lei: }\end{array}$ \\
\hline $\begin{array}{l}\text { V - incrementar, em sua área de atuação, o } \\
\text { desenvolvimento científico e tecnológico; }\end{array}$ & $\begin{array}{l}\text { V - incrementar, em sua área de atuação, o desenvolvimento } \\
\text { científico e tecnológico e a inovação; (Redação dada pela } \\
\text { Emenda Constitucional } n^{\circ} 85 \text {, de 2015) }\end{array}$ \\
\hline
\end{tabular}

Fonte: Elaboração do autor. 


\section{A CONSTITUCIONALIZAÇÃO DA CIÊNCIA, TECNOLOGIA E INOVAÇÃO COMO INSTRUMENTO DE EFETIVAÇÃO DO DIREITO A INOVAÇÃO}

A alteração Constitucional, estabeleceu ainda, que o Poder Público concederá apoio financeiro às atividades de pesquisa, de extensão e de estimulo e fomento à inovação realizadas não apenas por universidades, mas também por instituições de educação profissional e tecnológica.

\section{Antes}

Art. 213. Os recursos públicos serão destinados às escolas públicas, podendo ser dirigidos a escolas comunitárias, confessionais ou filantrópicas, definidas em lei, que:

§ 20 As atividades universitárias de pesquisa e extensão poderão receber apoio financeiro do Poder Público.

Fonte: Elaboração do autor.

Em razão do texto inserido pela Emenda Constitucional, fica clarividente que o Estado deve estimular a formação e o fortalecimento da inovação nas universidades, bem como nos demais entes públicos ou privados, assim como a criação e manutenção de parques e polos tecnológicos promotores da inovação, difusão e transferência de tecnologia.

Da leitura dos referidos artigos, percebe-se que nossa ordem constitucional propende atingir a "autonomia tecnológica", devendo que o Estado promova e incentive à ciência, à pesquisa e à tecnologia. É necessário destacar, que a Emenda Constitucional no 85, de 26 de fevereiro de 2015, reforçou ainda mais a atuação do Estado no campo da Ciência e da Tecnologia, para inserir no texto constitucional o dever estatal na promoção da Inovação e determinar ao Estado a adoção de políticas públicas destinadas a promover e incentivar, além do desenvolvimento científico, a pesquisa, a capacitação científica e tecnológica, também a Inovação.

Por força da Emenda Constitucional, os artigos 218 e 219 tiveram sua redação alterada e a pesquisa científica básica e tecnológica recebeu uma ampliação de prioridade, tendo em vista o bem público e o progresso da ciência, tecnologia e inovação.

Podemos dizer que sob o Título Da ciência e tecnologia, o capítulo antes era ordenado por dois artigos, o 218 e 219; o 218 era constituindo por cinco parágrafos e o segundo, apenas pelo caput. Nesse interim, o artigo 218 da Carta Maior passou a ter a seguinte redação:

\begin{tabular}{|c|c|}
\hline Antes & Atualmente \\
\hline $\begin{array}{l}\text { Art. 218. O Estado promoverá e incentivará o } \\
\text { desenvolvimento científico, a pesquisa e a } \\
\text { capacitação tecnológicas. }\end{array}$ & $\begin{array}{l}\text { Art. 218. O Estado promoverá e incentivará o } \\
\text { desenvolvimento científico, a pesquisa, a capacitação } \\
\text { científica e tecnológica e a inovação. (Redação dada pela } \\
\text { Emenda Constitucional } \mathrm{n}^{\circ} 85 \text {, de } 2015 \text { ) }\end{array}$ \\
\hline
\end{tabular}


$\S 10$ A pesquisa científica básica receberá tratamento prioritário do Estado, tendo em vista o bem público e o progresso das ciências.

$\S 3^{\circ}$ O Estado apoiará a formação de recursos humanos nas áreas de ciência, pesquisa e tecnologia, e concederá aos que delas se ocupem meios e condições especiais de trabalho.

Não havia $\S 6^{\circ}$

Não havia $\S 7^{\circ}$
$\S 1^{\circ}$ A pesquisa científica básica e tecnológica receberá tratamento prioritário do Estado, tendo em vista o bem público e o progresso da ciência, tecnologia e inovação. (Redação dada pela Emenda Constitucional nº 85, de 2015) $\S 3^{\circ} \mathrm{O}$ Estado apoiará a formação de recursos humanos nas áreas de ciência, pesquisa, tecnologia e inovação, inclusive por meio do apoio às atividades de extensão tecnológica, e concederá aos que delas se ocupem meios e condições especiais de trabalho. (Redação dada pela Emenda Constitucional $\mathrm{n}^{\circ} 85$, de 2015)

$\S 6^{\circ} \mathrm{O}$ Estado, na execução das atividades previstas no caput, estimulará a articulação entre entes, tanto públicos quanto privados, nas diversas esferas de governo. (Incluído pela Emenda Constitucional $n^{\circ} 85$, de 2015)

$\S 7^{\circ} \mathrm{O}$ Estado promoverá e incentivará a atuação no exterior das instituições públicas de ciência, tecnologia e inovação, com vistas à execução das atividades previstas no caput. (Incluído pela Emenda Constitucional n ${ }^{\circ} 85$, de 2015)

Fonte: Elaboração do autor.

O artigo 219, por sua vez, passou a apresentar o seguinte comando:

Não havia parágrafo único

\section{Atualmente}

Art. 219. O mercado interno integra o patrimônio nacional e será incentivado de modo a viabilizar o desenvolvimento cultural e sócio-econômico, o bem-estar da população e a autonomia tecnológica do País, nos termos de lei federal.

Parágrafo único. O Estado estimulará a formação e o fortalecimento da inovação nas empresas, bem como nos demais entes, públicos ou privados, a constituição e a manutenção de parques e polos tecnológicos e de demais ambientes promotores da inovação, a atuação dos inventores independentes e a criação, absorção, difusão e transferência de tecnologia. (Incluído pela Emenda Constitucional no 85, de 2015)

Fonte: Elaboração do autor.

Frisa-se, que com o advento da emenda, foi regulamentado instrumentos de cooperação entre órgãos e entidades públicas e entidades privadas, inclusive para o compartilhamento de recursos humanos especializados para execução de projetos de pesquisa, de desenvolvimento científico, tecnológico e de inovação.

\begin{tabular}{|c|c|}
\hline Antes & Atualmente \\
\hline Não havia Artigo 219-A & $\begin{array}{l}\text { Art. 219-A. A União, os Estados, o Distrito Federal e os } \\
\text { Municípios poderão firmar instrumentos de cooperação com } \\
\text { órgãos e entidades públicos e com entidades privadas, } \\
\text { inclusive para o compartilhamento de recursos humanos } \\
\text { especializados e capacidade instalada, para a execução de } \\
\text { projetos de pesquisa, de desenvolvimento científico e } \\
\text { tecnológico e de inovação, mediante contrapartida financeira } \\
\text { ou não financeira assumida pelo ente beneficiário, na forma } \\
\text { da lei. (Incluído pela Emenda Constitucional } n^{\circ} 85 \text {, de } \\
\text { 2015) }\end{array}$ \\
\hline
\end{tabular}

Fonte: Elaboração do autor. 
É importante destacar, que com o advento da EC, o Estado passou a ter uma responsabilidade de estimular a articulação entre entidades, tanto públicas quanto privadas, nas diversas esferas de governo, bem como de promover e incentivar a atuação no Sistema Nacional de Ciência, Tecnologia e Inovação - SNCTI.

\begin{tabular}{|c|c|}
\hline Antes & Atualmente \\
\hline Não havia Artigo 219-B & $\begin{array}{l}\text { Art. 219-B. O Sistema Nacional de Ciência, Tecnologia e } \\
\text { Inovação (SNCTI) será organizado em regime de } \\
\text { colaboração entre entes, tanto públicos quanto privados, com } \\
\text { vistas a promover o desenvolvimento científico e } \\
\text { tecnológico e a inovação. (Incluído pela Emenda } \\
\text { Constitucional no }{ }^{\circ} 85 \text {, de } 2015 \text { ) }\end{array}$ \\
\hline Não havia $\S 1^{\circ}$ & $\begin{array}{l}\S 1^{\circ} \text { Lei federal disporá sobre as normas gerais do SNCTI. } \\
\text { (Incluído pela Emenda Constitucional } n^{\circ} 85 \text {, de } 2015 \text { ) }\end{array}$ \\
\hline Não havia $§ 2^{\circ}$ & $\begin{array}{l}\S 2^{\circ} \text { Os Estados, o Distrito Federal e os Municípios } \\
\text { legislarão concorrentemente sobre suas peculiaridades. } \\
\text { (Incluído pela Emenda Constitucional } n^{\circ} 85 \text {, de } 2015 \text { ) }\end{array}$ \\
\hline
\end{tabular}

Fonte: Elaboração do autor.

Esse arcabouço legal reforçou ainda mais a atuação do Estado no campo da Ciência e da Tecnologia, para inserir no texto constitucional o dever estatal na promoção da Inovação e determinar ao Estado a adoção de políticas públicas destinadas a promover e incentivar, além do desenvolvimento científico, a pesquisa, a capacitação científica e tecnológica, também a Inovação, como veremos a seguir que é a estrutura constitucional e legal que dá suporte a política institucional, bem como a Estratégia Nacional de Ciência, Tecnologia e Inovação.

Podemos dizer, portanto, que os artigos 218 e 219 e posteriormente a Emenda Constitucional 85, dão o fundamento constitucional de nossa atual Política Nacional de Inovação Tecnológica.

\section{CONSIDERAÇÕES FINAIS}

Sociedade do conhecimento, revolução tecnológica, sistemas de inovação, estes, entre outros temas são tratados de forma recorrentes hoje em dia e seja qual for o enfoque que se privilegie, há uma forte convergência sobre o papel-chave que atualmente desempenham a Ciência, Tecnologia e Inovação (CTI) na edificação da sociedade contemporânea e de como o avanço do conhecimento e dessas inovações podem auxiliar a sociedade a enfrentar grandes desafios. 
A sociedade tecnológica requer inovação, em qualquer lugar, a qualquer tempo, por qualquer pessoa, o que potencializa a geração destes ativos intangíveis. A mudança tecnológica é uma mudança social e comportamental, logo, o direito de inovações compreenderá as relações jurídicas que se estabelecem em face da tecnologia.

Deste modo entende-se que o desafio para o direito em matéria de CTI é tratar e proteger o bem intangível e incorpóreo, cabe ao pensamento jurídico se debruçar em proteger a informação, entendida como um ativo, um novo modelo de riqueza contemporâneo. Nesse sentido, podemos dizer que o país passa por uma transição em seu marco institucional de Ciência, Tecnologia e Inovação, como já citado ao longo desta pesquisa.

Essas mudanças legislativas, buscam diminuir as lacunas existentes no Brasil tentando colocar a nação nos trilhos do desenvolvimento tecnológico e para isso requer a incorporação de novos atores e arranjos institucionais. Ficou claro que estas alterações ainda correntes levam cada vez mais a urgência de buscar novo modelos sociais.

Dessa forma, a Tecnologia e a Inovação são meios fundamentais e indispensáveis para o progresso científico de um País e com a Constitucionalização da Ciência, Tecnologia e Inovação o Brasil busca instrumentos para produzir inovações tecnologias de forma competitiva.

É notório, que a importância normativa que foi dada pelos legisladores constituintes à Ciência e a Tecnologia na Constituição Federal de 1988, teve influência no tratamento que posteriormente foi dado a matéria. Nesse interim, o estudo das Normas que compõem a Política Institucional de Inovação insere-se na esteira das necessidades urgentes relacionadas aos profissionais do Direito, já que diante de todo esses desafios, fica clarividente que o país precisava modernizar seu arcabouço legal para assegurar o desenvolvimento tecnológico e impulsionar à inovação.

A partir das pesquisas que foram realizadas, pode-se observar que mesmo com toda lacuna em torno de uma normatização relativamente recente o País tem buscado alternativas para a proteção desse conhecimento produzido. Nesse sentido, cumpre destacar a importância de conhecer o Arcabouço Legal de Ciência, Tecnologia e Inovação para operar em conformidade com o que está amparado legalmente pelo ordenamento jurídico. Dessa maneira, os profissionais comprometidos com a Inovação poderão atuar de forma mais 
dinâmica e com uma maior segurança, diminuindo os conflitos pelo desconhecimento de direitos e obrigações referentes ao tema.

É salutar esclarecer, que embora seja extremamente importante a criação de normas que visem a regulamentação da Ciência, Tecnologia e Inovação, seria um grande erro acreditar que estas sozinhas teriam o condão de resolver os problemas de Inovação da Universidade. Afinal, a Política Institucional não é determinada apenas com a criação de regulamentação própria.

Assim, a criação e o fortalecimento da politica institucional de inovação não dependem somete dos ajustes legais, é preciso, ampliar o diálogo incorporando as prioridades de CTI na agenda do país, proporcionando uma maior autonomia e a busca de maiores incentivos a inovações tecnológicas.

Não há duvida que o Estado vem buscando suprir as lacunas existentes. Entretanto, ainda há diversos aspectos que necessitam ser aperfeiçoados. Faz jus que se coloque em evidência que é importante construir outros elementos para consolidar base institucional de nossa política, para construir uma Política de CTI efetiva exige que o país, passe por uma profunda revisão na busca da excelência na formação dos profissionais que vão assumir os papeis de agentes de inovação e, tanto quanto possível, ter participação no desenvolvimento científico e tecnológico e na geração de inovações.

\section{REFERÊNCIAS}

BASTOS, Celso Ribeiro. MARTINS, Ives Gandra. Comentários a Constituição do Brasil: promulgada em 5 de outubro de 1988; Celso Ribeiro Bastos, Ives Gandra Martins. São Paulo: Saraiva 1999.8 v. art. 193 a 232.

BRASIL. Constituição (1824) Constituição Política do Império do Brazil. Rio de Janeiro, 1824. Disponível em < http://www.planalto.gov.br/ccivil_03/Constituicao/Constitui\%C3\%A7ao24.htm>. Acesso em 24 out.2006.

Constituição (1891) Constituição da República dos Estados Unidos do Brasil.

Rio de Janeiro, 1891. Disponível em < http://www.planalto.gov.br/ccivil_03/Constituicao/Constitui\%C3\%A7ao91.htm>. Acesso em 24 out. 2017. 
Constituição (1934) Constituição da República dos Estados Unidos do Brasil.

Rio de Janeiro, 1934. Disponível em <

http://www.planalto.gov.br/ccivil_03/Constituicao/Constitui\%C3\%A7ao34.htm>. Acesso em 24 out. 2017.

Constituição (1946) Constituição dos Estados Unidos do Brasil. Rio de Janeiro, 1946. Disponível em <

http://www.planalto.gov.br/ccivil_03/Constituicao/Constitui\%C3\%A7ao46.htm>. Acesso em 24 out. 2017.

Constituição (1967) Constituição da República Federativa do Brasil. Brasília, 1967. Disponível em <

http://www.planalto.gov.br/ccivil_03/Constituicao/Constitui\%C3\%A7ao67.htm>. Acesso em 24 out. 2017.

Constituição (1967) Emenda Constitucional n.1, de 24 de janeiro de 1969.

Brasília, 1969. Disponível em <

http://www.planalto.gov.br/ccivil_03/Constituicao/Emendas/Emc_anterior1988/e mc0169.htm>. Acesso em 24 out. 2017.

Constituição da República Federativa do Brasil: 1988. 34 ed. Brasília: Câmara dos Deputados, Coordenação de Publicações, 2017.

MIRANDA, Francisco Cavalcanti Pontes de. Comentários a Constituição de 1967; com a Emenda n. 1 de 1969. 3ed. Rio de Janeiro: Forense, 1987.

SILVA, Cylon Gonçalves da; MELO, Lúcia Carvalho Pinto de (Org.). Ciência, Tecnologia e Inovação Desafio para a Sociedade Brasileira: Livro Verde. Brasília: Academia Brasileira de Ciências, 2001. 250 p.

SILVA, Rosa Eliane Dias Rodrigues. Ciência e Tecnologia nas Constituições Brasileiras. da vinculação de receitas: o caso das fundações de apoio à pesquisa - FAPs. 2008. $159 \mathrm{f}$. Dissertação (Mestrado) - Curso de Política e Gestão em Ciência e Tecnologia, Centro de Desenvolvimento Sustentável, Universidade de Brasília, Brasília, 2008. Cap. 1. Disponível em: 〈http://repositorio.unb.br/bitstream/10482/4160/1/RosaEliane_orig.pdf>. Acesso em: 25 fev. 2017.

TIGRE, Paulo Bastos. Gestão da inovação: a economia da tecnologia no Brasil. Rio de Janeiro: Elsevier Editora, 2006.

ZISMAN, Célia Rosenthal. A liberdade de Expressão na Constituição Federal e suas limitações - Os limites dos limites. São Paulo, Editora Livraria Paulista, 2003. 